\title{
Chemical Composition of Suaeda vermiculata Seeds Grown in Hormozgan in the South of Iran
}

\author{
Shaghayegh Sefidanzadeh${ }^{1}$, Parisa Ziarati ${ }^{2 *}$ and Saeed Mohammadi Motamed ${ }^{3}$ \\ ${ }^{1}$ Pharmaceutical Sciences Research Center, Pharmaceutical Sciences Branch , \\ Islamic Azad university, Tehran-Iran (IAUPS) \\ ${ }^{2}$ Department of Medicinal Chemistry, Faculty of Pharmacy, Pharmaceutical \\ Sciences Branch, Islamic Azad University, Teahran-Iran (IAUPS) \\ ${ }^{3}$ Department of Pharmacognosy, Faculty of Pharmacy, Pharmaceutical Sciences Branch, \\ Islamic Azad University, Tehran - Iran (IAUPS).
}

DOI: http://dx.doi.org/10.13005/bbra/1858

(Received: 01 October 2015; accepted: 13 November 2015)

\begin{abstract}
There are 26 families of halophytes species in Iran and more than $70 \%$ of them has belonged to the Chenopodiaceae family. The leaf of halophytes has been used as a medicine for hepatitis and antiviral activity. The young leaf of it often mixed with other vegetable to reduce their saltiness. Elemental food composition data are important for both consumers and health professionals. Literature survey revealed that no investigation has been done on Suaeda Vermiculata grown in the Hormozgan province by now. The aim of this study was determination of proximate composition, mineral elements contents in this endemic Iranian seed. S.vermiculata were collected in August 2014 from Bandar Abbas, Hormozgan Province, Iran and samples was identified by R. Asadpour and voucher was deposited in the Herbarium of Faculty of Pharmacy, Pharmaceutical Sciences Branch, Islamic Azad University (IAUPS).Concentrations of some elements containing $\mathrm{Na}, \mathrm{K}, \mathrm{Li}$, $\mathrm{Se}, \mathrm{Cu}, \mathrm{P}, \mathrm{I}, \mathrm{Mg}, \mathrm{Ca}, \mathrm{Al}, \mathrm{B}, \mathrm{Mn}$, Fe and $\mathrm{Zn}$ were analyzed in S.Vermiculata samples by atomic absorption spectroscopy by standardized international protocols in Research Laboratory in Pharmaceutical Sciences Branch, Islamic Azad University. Obviously in $S$. vermiculata, the amount of the mineral element contents are high in comparison by other seeds studied in other countries, even the value of potassium, iron and Manganese in $S$. vermiculata grown in Hormozghan were ten times higher than seeds grown in Bushehr as different region of South of Iran. In this study, the nutritive value of $S$. vermiculata seed native to Hormozghan province in the south of Iran was determined and results revealed that it is so rich in mineral elements especially Iron. Therefore it could be recommended as a raw material for various industries but also would serves as useful dietary supplements.
\end{abstract}

Key words: Suaeda Vermiculata Seeds, Mineral elements, Iran, Hormozghan

Trace elements in soils result from the weathering of rocks and minerals in the soil parent material. The concentration of trace elements in different parent rocks is especially important in soils of undeveloped arid and semi-arid zones $^{1-2}$. Trace elements can be mobilized from arid soils

\footnotetext{
* To whom all correspondence should be addressed. Tel: +98-21-22600037; Fax: +98-21-22633986; E-mail: Ziarati.p@iaups.ac.ir
}

through plant uptake and erosion/leaching processes, but these soils usually contain higher contents of trace elements than other soils ${ }^{3}$. Some elements are highly immobile in nature and do not degrade biologically and, therefore, are persistent in soils and sediments. Residence times depend on the climate and can range from few decades in tropical areas to thousands of years in arid regions ${ }^{4}$. Trace element problems in agricultural soil (both deficiencies and toxicities) are associated with soil 
properties such as $\mathrm{pH}$, soil texture, cation exchange capacity (CEC), and Fe/Mn content, which are mostly inherited from the soil parent material. More siliceous parent material will result in sandier soils with lower fertility, while mafic rocks release the greatest quantity of basic cations and, therefore, influence soil fertility ${ }^{3,5-6}$. Halophyte plant species vary considerably in their nutritive value. Information on forage quality of halophytes in each phenological stage could help range managers choose suitable plant species for cultivation and also determine suitable grazing time to achieve higher animal performance in saline rangelands ${ }^{7}$. Suaeda Vermiculata and Suaeda aegyptiaca are common species of the genus Chenopodia. There are 26 families of halophytes species in Iran and more than $70 \%$ of them has belonged to the Chenopodiaceae family. They grow during both high and low tides from April to October. Some halophytes are also able to live in regions immersed with saline water. Tides immerse some regions seasonally, monthly, or daily, with a certain period and depth that depends on height. In response, halophytes increase the uptake of $\mathrm{Na}$ and decrease the uptake of $\mathrm{K}$ to their shoots; in addition, the activity of their fermentative enzymes is particularly high. Some halophytes are also compatible to live in immersion regions with saline water, for example coastal salt swamps ${ }^{8}$. The growth rates of S.vermiculata and S.aegyptiaca decreased after July and then increased after August. The leaf of halophytes has been used as a medicine for hepatitis and antiviral activity. The young leaf of it often mixed with other vegetable to reduce their saltiness ${ }^{8}$. Elemental food composition data are important for both consumers and health professionals. They contain moderate amounts of protein of which high percentage is in the form of soluble proteins. They also contain high levels of ash and crude fiber. Plant secondary metabolites content of halophytes vary considerably from species to species and from season to another. All these factors have certain implications on the feeding and nutritional value of halophytes.

It is proposed that the increased salt intake and, hence, the osmotic pressure of the rumen may affect the microorganism population and metabolism The high salt content is perhaps the major negative component in halophytic species and may be a factor which limits dry matter intake (DMI) and also reduces digestibility ${ }^{9}$. Halophytic plant species vary considerably in their chemical composition and nutritive value. There is a lack of information about trace element concentrations in soils of southern Iran. Information on the content and distribution of trace elements in soil and parent materials is important for several reasons, including characterization and assessment of soil quality and health, evaluation of soil for crop growth as well as forage and livestock production, providing baseline information required to determine the environmental impact from accidental chemical spills, as well as environmental contamination risk assessment. The objectives of this paper are (1) To determine the concentration ranges of selected elements in S.Vermiculata seed, growing in Hormozgan province in the south of Iran (2) To assess the chemical composition of S.Vermiculata seed according to the characteristics of the soil properties and soil quality, and (3) to investigate relationships among and between elements and other soil properties.

\section{MATERIALSAND METHODS}

\section{Plant material}

S.vermiculata seeds were collected in August 2014 from Sarkhun village, Bandar Abbas, Hormozgan Province, Iran: (27²3’34" N 56²3’59" E, 100m). Specimen was identified by R. Asadpour and voucher was deposited in the Herbarium of Faculty of Pharmacy, Pharmaceutical Sciences Branch, Islamic Azad University (IAUPS) Tehran. Hormozgan province district is situated in the southeast of Iran. More than $70 \%$ of the province is covered by mountains and hills thus it is a mountainous region ${ }^{10-11}$. This province is located between northern latitude 25p 24' to 28p 57' and eastern longitude 53p 41' to 59p 15'. It occupies an area of $70697 \mathrm{~km} 2^{11-14}$.

The study area (BandarAbbas region in Hormozgan province) is located in northern costal zones of the Persian Gulf in south of Iran (Fig. 1). The extent of the study area was about 18,000 ha and was situated in mountain and hill area having elevation ranging from $860 \mathrm{~m}$ to $3,081 \mathrm{~m}$. Annual rainfall is $214 \mathrm{~mm}$, mean temperature is $24.33^{\circ} \mathrm{C}$, average maximum temperature is $31.25^{\circ} \mathrm{C}$, and average minimum is $17.35^{\circ} \mathrm{C}$. The soils of the study 
area are mostly shallow and therefore are only suitable as rangeland for herd grazing. According to the American system of soil taxonomy ${ }^{15}$, the soils of the region are classified in as Entisols.

Plain part of the region includes much of the southern, eastern and northern part of the strip consisted of alkaline and saline soils contain large amounts of soluble salts such as chloride, sulfate and carbonate of $\mathrm{Ca}, \mathrm{Mg}$, sodium, and potassium $^{14,15}$.

\section{Sampling Method}

The present study was carried out the common halophytes S. Vermiculata in early summer, 2014 S. Vermiculata is native to the south, southerneast and Persian Gulf coastal and are recognized as Tahma. After drying at $\left(95 \mathrm{C}^{\circ}\right)$ for $1 \mathrm{~h}$ to a constant weight, the samples were separated and weighed individually. The dried samples were homogenized and grounded using a mortar.

\section{Crude Fiber}

Five grams of the grounded S.Vermiculata mature dry seeds samples were digested in $50 \mathrm{ml}$ of $1.25 \% \mathrm{H}_{2} \mathrm{SO}_{4}$. The solutions were boiled for 45 minutes and then were filtered and washed with hot distilled water. The filtrates were digested in $50 \mathrm{ml}$ of $1.25 \%$ Sodium Hydroxide solutions. For 50 minutes these solutions were heated, filtered and washed with hot deionized water and over dried. The final oven-dried residues were ignited in a furnace at $550^{\circ} \mathrm{C}$. The weights of the left after ignition were measured as the fiber contents and were expressed in term of the weights of the samples before ignition ${ }^{14,16}$.

\section{Crude Protein}

The protein nitrogen in one gram of the dried samples were converted to ammonium sulphate by digestion with concentrated $\mathrm{H}_{2} \mathrm{SO}_{4}$ (Merck 96.5\%) and in the presence of $\mathrm{CuSO}_{4}$ and $\mathrm{K}_{2} \mathrm{SO}_{4}$ 20-21). The solutions were heated and the ammonia evolved were steam distilled into Boric acid $2 \%$. The nitrogen from ammonia were deduced from the titrations of the trapped ammonia with $0.1 \mathrm{M} \mathrm{HCl}$ with Tashirus indicator (methyl red: methylene blue 2:1) until a purplish pink color were obtained. Crude proteins were calculated by multiplying the valve of the deduced nitrogen by the factor $6.25 \mathrm{mg}^{13,14,17-18}$.

\section{Ash Content}

One gram of the oven-dried samples in powder from was placed in acid washed crucible by known weight. They were ignited in a muffle furnace for 5 hours at $550^{\circ} \mathrm{C}$. After cooling crucibles they were weighed and the ash contents were expressed in terms of the oven-dried weight of the sample $^{18}$.

\section{Zinc, Manganese, Copper and Potassium Determination}

All stock solutions and working standards were stored at $4^{\circ} \mathrm{C}$ and brought to room temperature $\left(25^{\circ} \mathrm{C}\right)$ before use. For Zinc, Manganese, Copper and Selenium concentration in S.Vermiculata, powered seed samples were dried in oven for 48 hours at a temperature of $85^{\circ} \mathrm{C}$. The samples were then ground and sieved through 0.5 $\mathrm{mm}$ sieve. The powdered samples then subjected to the acid digestion using concentrated nitric acid (65\% Merck), Sulfuric acid (96.5\% Merck) and per chloric acid (70\% sigma). Analar grade hydrogen peroxide (about 30\%) also was used for the digestion. Application of concentrated $\mathrm{HNO}_{3}$ along with thirty percent hydrogen peroxide $\mathrm{H}_{2} \mathrm{O}_{2}$ (Merck) for mineralization of samples to the complete digestion of samples ${ }^{12-14}$ following Environmental Protection Agency (EPA) Method 3052 was done ${ }^{19-}$ 21.

Two gram of air-dried of each homogeneously $\mathrm{S}$.Vermiculata samples accurately weighed and $30.0 \mathrm{~mL}$ of the digestion mixture (2 parts by weight of nitric acid: 1 parts of Sulfuric acid \& 4 parts by weight perchloric acid) and heated slowly by an oven and then rise the temperature. The remaining dry inorganic residues were dissolved in $30.0 \mathrm{~mL}$ of concentrated nitric acid and the solution used for the determination of trace and essential mineral elements. Blanks and samples were also processed and analyzed simultaneously. All the chemicals used were of analytical grade (AR). Standardized international protocols were followed for the preparation of material and analysis of heavy metals contents ${ }^{22-24}$. The samples were analyzed by Flame Emission Spectrophotometer Model AA-6200 (Shimadzu, Japan) using an airacetylene, flame temperature: $2800^{\circ} \mathrm{C}$, acetylene pressure: $0.9-1.0 \mathrm{bar}$, air pressure: $4.5-5 \mathrm{bar}$, reading time: $1-10 \mathrm{sec}$ (max $60 \mathrm{sec}$ ), flow time: $3-4$ sec (max $10 \mathrm{sec}$ ), using at least five standard solutions for each metal and determination of potassium content was followed by FDA Elemental analysis ${ }^{25}$. In order to verify of reliability of the measuring apparatus, periodic testing of standard 
solutions was performed. The accuracy was checked using quality control test for fungi and their substrate samples to show the degree of agreement between the standard values and measured values; the difference was less than $5 \%$.

\section{Iron Determination}

The aliquot was passed through the atomic absorption spectrophotometer to read the iron concentration. Standards were prepared with a standard stock of $10 \mathrm{mg} / \mathrm{L}$ using ferrous ammonium sulphate where 3 - $60 \mathrm{ml}$ of iron standard solution $(10 \mathrm{mg} / \mathrm{L})$ were placed in stepwise volumes in $100 \mathrm{ml}$ volumetric flasks. $2 \mathrm{ml}$ of hydrochloric acid were added and then brought to the volume with distilled water. The concentration of iron in the aliquot was measured using the atomic absorption spectrophotometer in $\mathrm{mg} / \mathrm{L}$. The whole procedure was replicated three times ${ }^{11-13}$.

Calcium, Sodium and Magnesium Determination

$5 \mathrm{ml}$ of the aliquot were placed in a titration flask using a pipette and diluted to $100 \mathrm{ml}$ with distilled water and subsequently $15 \mathrm{ml}$ of buffer solution, ten drops of Eriochrome black T indicator and $2 \mathrm{ml}$ of triethanolamine were added. The mixture was titrated with Ethylene-Diamine-Tetra-Acetate (EDTA) solution from red to clear blue $\mathrm{e}^{12-13}$.

\section{Selenium Determination}

Stock standard solutions for selenium were $1000 \mathrm{~g} / \mathrm{mL}$ solution. All reagents and standards were of analytical grade ( Merck, Germany).The palladium matrix modifier solution was prepared by the dilution $(10 \mathrm{~g} / \mathrm{L}) \mathrm{Pd}\left(\mathrm{NO}_{3}\right)_{2}$ and iridium AA standard solution, $1000 \mathrm{~g} / \mathrm{mL}$ in $20 \% \mathrm{HCl}, 0.1 \% \mathrm{~V} / \mathrm{V}$ nitric acid prepared by dilution trace pure $65 \%$ nitric acid and $0.1 \%$ Triton X-100 were used. Doubly distilled water was used in all operations. The samples were analyzed by Flame Emission Spectrophotometer Model AA-6200 (Shimadzu, Japan). The analyze performed according by Analytical Method ATSRD ${ }^{11-13,26-27}$. Crude Protein - Nitrogen Crude Protein (CP)

Nitrogen content was measured by modified Kjeldahl method (involving sulphuric acid digestion). It was assumed all $\mathrm{N}$ present in the feed was derived from protein and that all protein contains $16 \% \mathrm{~N}$. Thus $\mathrm{CP}=\mathrm{N} \times 100 / 16=\mathrm{N} \times 6.25^{28}$. Ether soluble Extract

An ether soluble extract was prepared by mixing the feed using petroleum ether for a defined period. The mixture was then filtered. The filtrate was allowed to evaporate and the remaining residue was weighed to determine the mass of the ether soluble extract $(\mathrm{EE})^{28}$.

\section{Crude Fiber}

Crude Fiber (CF) was measured by taking the residual food following ether extraction, and then boiling it with acid and then alkali for defined periods. The residue was then dried, weighed, ashed and weighed again. CF was weight of residue less weight of ash. CF equates to the indigestible part of ration (for non-ruminants) and consists of cellulose, hemicellulose, lignin, i.e. plant cell walls ${ }^{28}$.

\section{Nitrogen free extractive}

This is an indirect determination of the non-fiber carbohydrate content of the feed. Nitrogen free extractive (N-FE) as a percentage is $100 \%$ minus the rest. This will include sugars, starches, and water soluble vitamins (will also measure some cellulose, hemicellulose, resins, pigments, tannins, pectin ${ }^{28}$.

\section{RESULTSAND DISCUSSION}

The mean content of trace and essential mineral elements (mg/kg DW) in the mature dry seed of S.Vermiculata samples is shown in table 1 . The samples were analyzed by wet digestion method and standardized international protocols were followed for the preparation of material and analysis of mineral contents and analyzed by Atomic Absorption Spectrophotometer in Research Laboratory in Pharmaceutical Sciences Branch, Islamic Azad University.

Proximate composition and physicochemical characteristics of the samples has shown in table 2 , based on the fresh weight.

Obviously in S.vermiculata the order of amount of the some mineral element contents such as zinc copper, iron, and calcium are different in comparison by other S.vermiculata studied in Iran in recent study in Bushehr. Chamkouri et al. in 2015, studied the minerals of halophytes and S.Vermiculata in Bushehr area and concluded that the accumulation of $\mathrm{Na}$ was higher than those of $\mathrm{K}, \mathrm{Ca}$ and $\mathrm{Mg}^{29}$. Our data revealed that sodium content was higher than other metallic ions but not as much as in this seed growing in Busher. Asri et al. in 1997 studied the minerals of halophytes and concluded that the accumulation of Na was higher than those of $\mathrm{K}, \mathrm{Ca}$ and $\mathrm{Mg}^{30}$. The results 
Table 1. The Mean content (mg/kg DW) composition of the mature dry seeds of S.vermiculata from Hormozgan Province, Iran

\begin{tabular}{lccc}
\hline Minerals & Mean content $\pm \mathrm{SD}^{*}(\mathrm{mg} / \mathrm{Kg} \mathrm{DW})$ & Minerals & Mean content $\pm \mathrm{SD}^{*}(\mathrm{mg} / \mathrm{Kg} \mathrm{DW})$ \\
\hline Sodium & $103.44 \pm 2.103$ & Boron & $0.066 \pm 0.003$ \\
Potassium & $24.732 \pm 1.036$ & Phosphor & $2.005 \pm 0.002$ \\
Calcium & $0.882 \pm 0.012$ & Iodine & $0.582 \pm 0.001$ \\
Magnesium & $22.07 \pm 0.023$ & Manganese & $0.030 \pm 0.002$ \\
Iron & $11.42 \pm 0.006$ & Sulphur & $1.002 \pm 0.002$ \\
Copper & $0.102 \pm 0.001$ & Fluorine & $0.005 \pm 0.001$ \\
Selenium & $0.005 \pm 0.001$ & Lithium & $0.001 \pm 0.0002$ \\
Zinc & $0.052 \pm 0.004$ & Molybdenum & $0.001 \pm 0.0001$ \\
\hline
\end{tabular}

${ }^{*} \mathrm{SD}=$ Standard Deviation

Table 2. Proximate analysis of S.Vermiculata samples from Hormozgan Province, Iran

\begin{tabular}{lc}
\hline Nutrient & Percentage (\%) \\
\hline Dry Matter(DM) & 36.16 \\
Crude Protein (CP) & 15.79 \\
Crude Fiber (CF) & 3.14 \\
Ash & 8.78 \\
Fats / lipids (EE) & 5.59 \\
Nitrogen Free Extractives (NFE ) & 30.54 \\
\hline
\end{tabular}

showed that CP, CF, DMD and EE were 15.79, 3.4, $36.16 \%$ and $5.59 \mathrm{MJ} / \mathrm{Kg}$, respectively in the mature seed of S.Vermiculata.

As the amount of structural tissues in the stem of plants increases with increasing plant age, the amount of DMD becomes reduced ${ }^{31}$. (There is a close relationship between digestibility and cell wall characteristics: cell contents can be $100 \%$ digestible for animals and will not become reduced even when the plant matures. In contrast, the

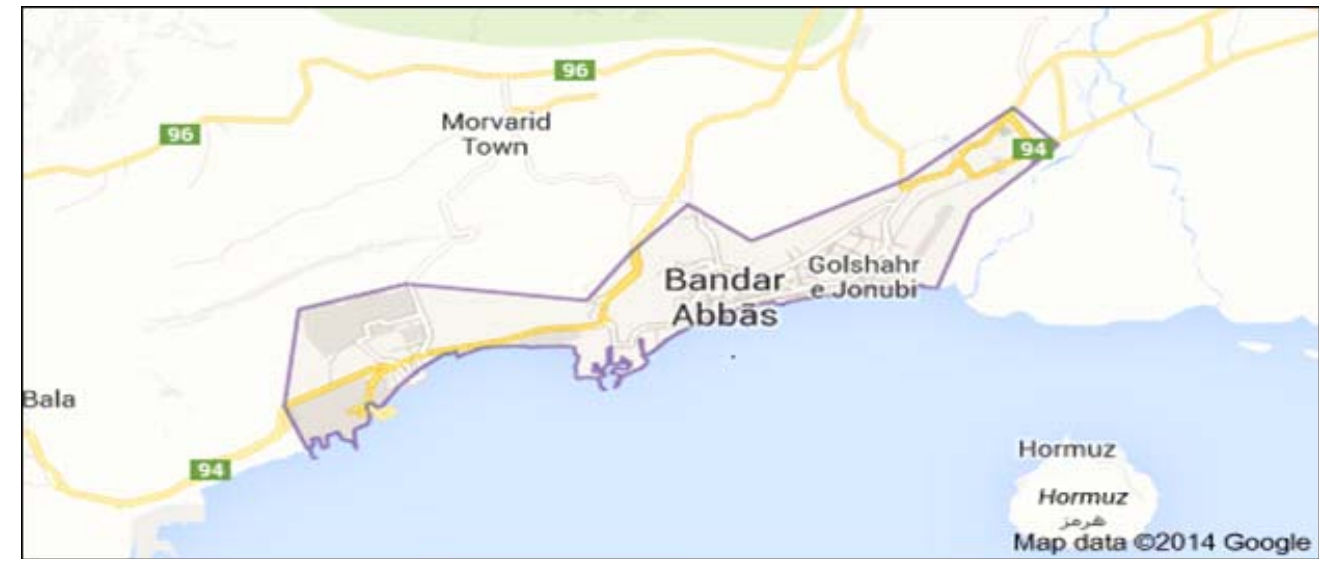

Fig. 1. Location of S.vermiculata samples collection

chemical composition of the cell wall changes as the plant grows, and fiber content increases and digestibility decreases, as was also reported by Asaadi and Yazdi ${ }^{31}$. Halophytes can play a significant role in the wellbeing of different peoples. The way in which halophytes are assessed will very much depend on which system dominates. Any evaluation must depend on viewing performance in the context (biological/ economic) in which it occurs. However, the shortage of animal feeds is the main constraint to increase indigenous animal production. It is a common characteristic in arid and semi-arid regions which is considered the main constraints to improve livestock productivity. In these areas, the animals often have to consume the only available feed resource which is halophytic plants ${ }^{32}$. Most of countries in these regions import large amounts of feed materials to 
cover the nutritional gap of animal and poultry which puts a heavy burden on the local governments and the farmers as well. It consequently decreases the net profits of animal investments operations due to the high costs of such feed materials. Improving nutritional status of desert grazing livestock (sheep, camels and goats) particularly during the prolonged dry seasons would increase the average annual animal production by approximately $27 \%{ }^{9,32}$. Therefore, intensive efforts have been directed to find alternative feed resources from halophytes. Unfortunately, unpalatable halophytes are widely dominant. The development of salt tolerant fodder crops may help address the scarcity of good quality water in many arid agricultural regions of the world ${ }^{9}$ mentioned that naturally occurring inland and coastal salt tolerant grasses have considerable potential as low cost nonconventional fodder crop. A number of saltbush species provide adequate nutrition with considerably preferred browse for domestic livestock. Halophytic plants such as $S$.Vermiculata, is generally considered extremely valuable as a fodder reserve during drought.

It has been long recognized that environmental conditions play a major role in determining the quantity and quality of nutrients produced by halophytes. It is reported that proteins level decreased under salinity is due to low uptake of nitrate ions ${ }^{33}$ and due to other factors. It is proposed that the increased salt intake and, hence, the osmotic pressure of the rumen may affect the microorganism population and metabolism ${ }^{9}$. Increasing osmotic pressure in the rumen is believed to be unfavorable to the growth of protozoa. Also, the increased rates of outflow are believed to contribute to decreased protozoal population.

The mineral elements in the halophytes were significantly different depending on the weather conditions during growth. Halophytes such as $S$. vermiculata have mechanisms that can adapt and select the critical ions from the soil. The mineral elements in halophytes are significantly changed during growth in different weather conditions. The achieved data from this study suggests the strong potential of $S$. vermiculata as an halophyte could be a strong source of mineral and trace elements and compounds with beneficial proprieties, and a promising source of health products for food and pharmaceutical industry.

\section{ACKNOWLEDGEMENT}

Authors are thankful to Mrs Mahtab Alimardan for technical assistance. Supports from Pharmaceutical Sciences Branch, Islamic Azad University (IAUPS) is gratefully acknowledged.

\section{REFERENCES}

1. Haluschak, P., Eilers, R.G., Mills, G.F., Grift, S. Status of selected trace elements in agricultural soils of southern Manitoba. Technical Report 1998-6E. Winnipeg: Land Resource Unit, Brandon Research Centre, Research Branch, Agriculture and Agri-Food Canada, University of Manitoba. 1998.

2. Fengxiang, X.H. Biogeochemistry of trace elements in arid environment. New York (NY): Springer-Verlag, 2007; 366.

3. Kabata-Pendias, A., Pendias, H. Trace element in soils and plants. 3rd ed. Boca Raton (FL): CRC Press. 2001.

4. McGrath, S.P. Long-term studies of metal transfer following the application of sewage sludge. In: Coughtrey PJ, Martin MH, editors. Pollutant transport and fate in ecosystems. Oxford: Blackwell Science; 1987; 301-317.

5. Abbaslou, H., Martin, F., Abtahi, A., Moore, F. Trace element concentrations and background values in the arid soils of Hormozgan Province of southern Iran, Archives of Agronomy and Soil Science, 2014; 60 (8): 1125-1143. DOI: 10.1080/ 03650340.2013 .864387$.

6. Salim, R. M., Sultana, S. A. Distribution and availability of copper fractions to wheat from some loess derived alkaline calcareous soils. JOURNAL OF AGRICULTURAL SCIENCE 1988;111(03). DOI: 10.1017/ S002185960008374X.

7. Zandi Esfahan 'E. , Assareh, M. H., Jafari , M., Jafari , A. A., Javadi, S. A. , Karimi, G. Phonological effects on forage quality of two halophyte species Atriplex leucoclada and Suaeda vermiculata in four saline rangelands of Iran . http://world-food.net/phonological-effectson-forage-quality-of-two-halophyte-speciesatriplex-leucoclada-and-suaeda-vermiculata-infour-saline-rangelands-of-iran/.

8. Chamkouri, N. Microwave Assisted Acid Digestion Method for the Determination of Some Heavy Metals in Halophyte Samples. 
International Research Journal of Applied and Basic Sciences. 2015; 9 (4): 612-615.

9. Attia-Ismail, S., A. Characterization of halophytes as animal feeds. Proc. 2end Intel. Conf. On the Modern Approaches on Livestock's Production Systems. Egypt, Oct 2015, 303-321.

10. Zaeifi, M. The flora of Hormozgan province. Bandar Abbas: Research Center of Agriculture and Natural Resources Publications. 2001 ; 1.

11. Iranian Geographical Administration. Geographical culture of Bandar Abbas villages, Iran. Vol. 122. Tehran: Iranian Ministry of Defence Publications; 1983.

12. Abbasian, K., Asgarpanah, J., Ziarati, P., Chemical Composition of Acacia Nilotica seed Growing Wild in South of Iran. Oriental Journal of Chemistry. 2015; 31(2):1027-1033.

13. Moghanloo, Z., Ziarati, P., Asgarpanah, J. Fatty Acid Profile of Acacia tortilis (Forssk.) Hayne Seed Oil Growing Wild in South of Iran. Oriental Journal of Chemistry. 2015; 31 (1): 489-491.

14. Zarei ,M., Asgarpanah, J., Ziarati, P. Chemical Composition profile of Wild Acacia oerfota (Forssk) Schweinf Seed Growing in the South of Iran. Oriental Journal of Chemistry. 2015; 31 (4). Avaialable from : http://www.orientjchem. org/?p=12161.

15. USDA. Soil taxonomy: Keys to soil taxonomy, Sixth Edition, 1994, p.177.

16. Aryapak, S., Ziarati, P. Nutritive Value of Persian Walnut (Juglans regia L.) Orchards. AmericanEurasian J. Agric. \& Environ. Sci. 2014, 14, 1228-1235.

17. Ziarati, P. Determination of some heavy metals in popular medicinal plants in Tehran's market Journal of Pharmaceutical and Health Sciences. 2012; 1(3): 31-36. 23.

18. Ziarati, P. Determination of Contaminants in Some Iranian Popular Herbal Medicines .Journal of Environmental \& Analytical Toxicology . 2012 ;2(1). Available from: http://dx.doi.org/ 10.4172/2161- 0525.1000120.

19. Ziarati, P., Khoshhal, Z., Asgarpanah, J., Qomi, M. Contaminations of Heavy Metals in Tea Leaves, Finished Tea Products and Liqour in Gilan Province, Iran. Intl J Farm \& Alli Sci. 2013; 2 : 383- 387.

20. Praveen, S. Application note Atomic Absorption, 2011. Available in site : www.perkinelmer.com.

21. Ziarati, P.; Tosifi, S. Comparing some physical and chemical properties of green olive (olea europea l.) in iran association with ecological conditions. International Journal of Plant, Animal and Environmental Sciences. 2014; 4(2):
519-528.

22. Ziarati, P.; Rabizadeh, H. The Effect of Thermal and Non Thermal of Food Processes and Cooking Method in Some Essential Mineral Contents in Mushroom (Agaricus bisporus) in Iran. J. Nov. Appl. Sci. 2013 ; 2 : 954-959.

23. AOAC (Association of Official Analytical Chemists). Wet digestion for non -volatile metals in: AOAC official methods of analysis, 1998, 16th edition, 4th revision, vol.1, chapter 9. p32.

24. Ziarati, P., Behbahani, P., Karbalaie Mohammad, N. Role of Unprofessional Storage methods on the heavy metal content of Rosa Damascena ( Gole Mohammadi) . Journal of Pharmaceutical and Health Sciences .2012;1(4): 73-78.

25. ORA Laboratory Manual FDA, 2004, 6. Document no.: iv-02, version no.: 1.5 , effective date: 10-01-03 REVISED: 02-14-13. Available in Site: http://www.fda.gov/downloads/ S c i ence Rese a r ch / F i eld S cience/ UCM092226.pdf.

26. Ziarati , P., Azizi, N. Consequences of cooking method in essential and heavy metal contents in brown and polished alikazemi rice .International Journal of Plant, Animal and Environmental Sciences. 2014; 4: 280-287.

27. Masamba, K.G. ; Kazombo-Mwale, R. Determination and comparison of nutrient and mineral contents between cultivated and indigenous edible mushrooms in Central Malawi .African Journal of Food Science .2010; 4: 176179.

28. Association of Official Analytical chemists, Official methods of analysis. USA: Washington, DC. 1990.

29. Narges Chamkouri, Masoud Torabpour, Farokh Ghafarizadeh. Microwave assisted digestion coupled with inductively coupled plasma optical emission spectrometry for determining element concentrations in halophytes. J Bas Res Med Sci 2015; 2(1):49-56.

30. Asri, Y. ,Ghorbanli, M. The halophilous vegetation of the Orumieh lake salt marshes, Iran. Plant Ecol. 1997; 132(1):155-70.

31. Asaadi AM, Yazdi AK, Phenological stage effects on forage quality of four forbs species. J Food Agric Environ. 2011; 9(2): 380-384.

32. Attia-Ismail, S.A., Elsayed, H.M., Asker, A.R., Zaki, E.A. Effect of different buffers on rumen kinetics of sheep fed halophyte plants. Journal of Environmental Science, 2009; 19 (1):89-106,

33. Agastian, P., Kingsley, S. J., Vivekanandan, M. Effect of salinity on photosynthesis and biochemical characteristics in mulberry genotypes. Photosynthetica, 2000; 38: 287-290. 